\title{
Pupal Period Affects Calling Behavior of the Wheat Moth, Pseudaletia sequax (Lepidoptera: Noctuidae)
}

\author{
Ângela A. Almeida, Eraldo R. Lima \& Ronaldo Reis Jr
}

Departamento de Biologia Animal, Setor Entomologia, Laboratório de Semioquímicos, Universidade Federal de Viçosa, Viçosa, Minas Gerais, Brazil

\author{
Correspondence \\ Ângela A. Almeida, Departamento de Biologia \\ Animal, Laboratório de Semioquímicos, \\ Universidade Federal de Viçosa, Avenida Ph. \\ Rolfs s/n, 36570-000 Viçosa, Minas Gerais, \\ Brazil. \\ E-mail: aaamoth@gmail.com \\ Received: September 2, 2007 \\ Initial acceptance: October 10, 2007 \\ Final acceptance: January 24, 2008 \\ (S. Forbes) \\ doi: $10.1111 / j .1439-0310.2008 .01492 . x$
}

\begin{abstract}
The effects of pupal period and age on calling behavior of virgin females of Pseudaletia sequax were determined. Calling behavior of groups of females of similar age of pupation was observed every $10 \mathrm{~min}$ for six calling days. Females were considered calling when they assumed a characteristic position: wings and abdomen elevated, displaying the ovipositor and presumably releasing pheromone. Calling behavior was discontinuous. Females with a shorter pupal period took more time to start calling than females with a longer pupal period and called for a longer period. On the first day of calling, females took more time to initiate calling, on average during the seventh hour of the scotophase, whereas on the second day of calling, most females initiated calling during the fifth hour of the scotophase. On subsequent days of calling, the average time to initiate calling changed to the fourth hour of the scotophase. The mean time of calling per day decreased significantly with the number of days since first calling, and the mean number of calling bouts increased with days since first calling.
\end{abstract}

\section{Introduction}

Mating in moths generally depends on the expression of a series of behavioral patterns. In females, these behaviors include the emission of volatile sex pheromones (calling behavior) that leads to attraction of potential mates and receptivity to (acceptance of) males that attempt mating. Pheromones are chemicals produced in specialized glands or specialized cells; they are released by individuals and induce responses such as orientation, pre-copulatory behavior and mating in the other gender of the same species (Cardé \& Baker 1984; Kingan et al. 1993).

Calling is the release of the sex pheromone by female moths, which begins at the attainment of sexual maturity. In Noctuidae, calling is conspicuous: females extrude their ovipositors intermittently or continuously and fan their wings. Females assume a characteristic position optimizing the dispersion of volatile sex pheromones into the environment, which leads to the attraction of males and enhances the probability of mating (Han $\delta$ Gatehouse 1991a).

Pseudaletia sequax is an important pest, attacking wheat and forage crops in South America and in southern Brazil. Until now, there have been no reports on the reproductive biology of this moth. We investigated the calling behavior of $P$. sequax to determine the age at which females start calling following emergence, the average time that females remain calling, the influence on the duration of the pupal period on the calling behavior and average number of calling bouts.

\section{Methods}

The study was carried out between Feb. and Mar. 2006. Larvae of $P$. sequax were collected from wheat crops in southern Brazil and reared on an artificial diet (Salvadori \& Parra 1990) with $10 \mathrm{ml}$ of soy oil added as a complement of protein, fat acid and 
sterols. The first generation emerging in the laboratory was used for the experiments described here. After pupation, 90 female pupae of the same age and size were separated and isolated. After emergence, newly emerged virgin females were placed in individual plastic numbered cages. These cages were covered with cloth to permit circulation of air. The moths were supplied with a sugar-water solution of $10 \%$.

\section{Bioassays}

The experiment was performed in a dark room at temperature of $25 \pm 5^{\circ} \mathrm{C}$ under reversed photoperiod (12D:12L) and a relative humidity of $70 \pm 5 \%$. Ninety pupae were observed daily to verify adult emergence and calculation of the duration of pupal period. Subsequently, 90 adult females were observed every $10 \mathrm{~min}$ throughout the scotophase to determine at what age calling was initiated. Moths were considered calling if the ovipositor was at least partially extended, because the sex pheromone in $P$. sequax is produced in specialized glands or specialized cells, located in ovipositor region.

All emerged females were observed during the scotophase following eclosion, the day on which a female first displayed calling behavior was designated as calling day 1 , and subsequent days were designated as calling day 2, 3, .., 6 respectively. Ninety females were observed for six calling days or until female death. Thus, the calling behavior of females calling for the first time could be compared, regardless of differences in age since emergence and similar comparisons were made for subsequent calling days. If the females were calling during two consecutive observations, they were considered to have been calling for $20 \mathrm{~min}$; if females called only one of two consecutive observation the calling period was considered $10 \mathrm{~min}$. We used this information to obtain the mean onset of calling, the total time spent calling and the number of calling bouts.

\section{Statistical Analyses}

All statistical analyses were performed in $\mathrm{R}$ statistical system (R Development Core Team, 2006), using generalized linear modeling mixed effects and Poisson errors with log link (Crawley 2002), to obtain: mean time for first calling, the amount of time the females called and calling bouts. We use mixed models to remove the effect of temporal pseudo-replication. The pupal period was calculated using linear modeling, followed by residual analyses to verify error distribution and suitability of the models employed, including checks for over-dispersion. Full models were built by including all variables and their interactions according to term complexity, starting from simplest one. All model simplification was achieved by extracting non-significant terms $(p>0.05)$ from model according to their respective complexity, starting from the most complex one. When two non-significant terms presented the same complexity, the one explaining less deviance was extracted first. Each term deletion was followed by an ANOvA with F-test, in order to recalculate the deviance explained by remaining terms.

\section{Results}

Calling females were easily recognized, as they raised their wings slightly above the abdomen, fully extruded their ovipositor and fluttered their wings. In general, they oriented vertically (head highest) during calling. When calling, females constantly vibrated their wings and extruded their ovipositors intermittently and in a discontinuous pattern.

There was considerable variation in emergence of pupae of the same age emerged on different days; females emerging on the same day were grouped. The number of insects that emerged each day after pupation was: 9, 9, 14, 24, 15, 10 and 9 on the fifth to the 11 th day respectively.

As not all females initiated calling at the same chronological age, we propose individual comparisons by 'days since first calling'. Thus, the calling behavior of females calling for first time was compared, regardless of differences in age since emergence and similar comparisons were made for subsequent calling days.

Females that had emerged on the fifth day after pupation took more time to initiate calling than females that spent more time in the pupal stage. Hence, the day of first calling was influenced by the pupal period (Fig. 1).

We observed that the time until the start of calling was longer on the first calling day, whereas it decreased on subsequent calling days (Fig. 2). On the first calling day, females on average initiated calling during the seventh hour of the scotophase, whereas they started calling during the fifth hour of the scotophase on the second calling day (2). On subsequent calling days, they initiated calling on average during the fourth hour of the scotophase. The average time that the females remained calling increased with calling days, hence, with physiological age. The daily calling period differed significantly in subsequent calling days. The total calling time 


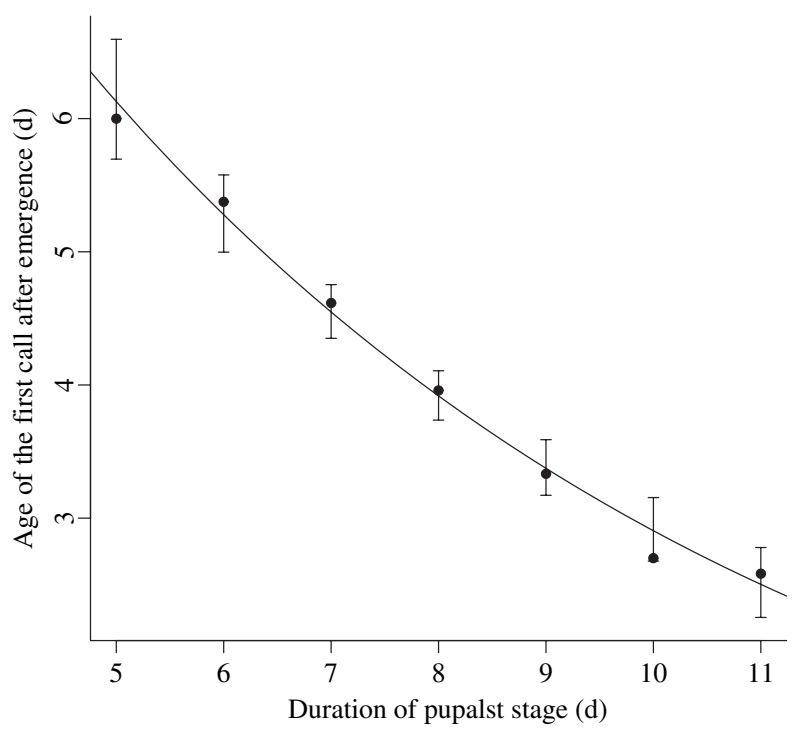

Fig. 1: Relationship between duration of pupal stage and age of first calling after emergence of virgin females of Pseudaletia sequax. In $25 \pm 5^{\circ} \mathrm{C} ; 12 \mathrm{D}: 12 \mathrm{~L}$ and $70 \% \mathrm{RH}(\mathrm{n}=90)$, F-value $=133.17$, $\mathrm{p}$-value $=$ $2.2^{-16}$.

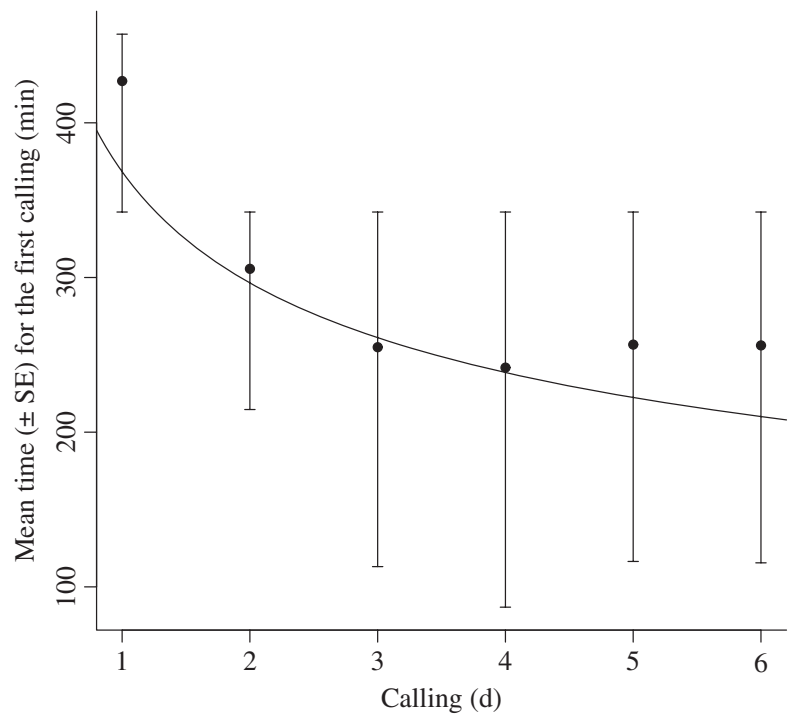

Fig. 2: Relationship between days since first calling (calling days) and onset time of calling from virgin females of Pseudaletia sequax in the scotophase at a temperature of $25 \pm 5^{\circ} \mathrm{C}$ under a photoperiod of $12 \mathrm{D}: 12 \mathrm{~L}$ and of $70 \% \mathrm{RH},(\mathrm{n}=90)$. F-value $71.31, \mathrm{p}$-value $=0.0001$.

was negatively affected by pupal period (Fig. 3). The mean number of bouts increased with days since first calling (Fig. 4).

\section{Discussion}

Although all females pupated at the same time, females of $P$. sequax that had emerged earlier took more time to initiate calling compared with females that emerged later (Fig. 1). We also observed that the calling pattern was discontinuous, intermittent and females did not adopt a stationary posture. Intermittent calling has been associated with higher concentrations of pheromone produced (Turgeon $\delta$ McNeil 1983). We also found that the time spent calling was shorter with increasing age since first calling (Fig. 2) and that the number of calling bouts increased with days since first calling (Fig. 4).

One explanation for the precocious calling by females of $P$. sequax that emerged later after pupation is that pheromone biosynthesis and chemical communication is under endocrine control and dependent of time since pupation. Possibly, females emerge physiologically more mature after a longer pupal period than after a shorter period and therefore start calling earlier (Fig. 1). Several studies showed that the regulation and activation of the biosynthesis of sex pheromones in moths are under control of hormonal systems (Raina \& Klun 1984; Cusson \& McNeil 1989; Han \& Gatehouse 1991b; Cusson et al. 1993; Picimbon et al. 1995; Rafaeli \& Bober 2005).

We observed that, as moths aged, the calling length and the mean number of calling bouts were higher (Figs 3 and 4). Similar results were obtained with Pseudaletia unipucta (Turgeon \& McNeil 1982, 1983; Hou \& Sheng 2000). Generally, calling and courtship behaviors depend on ovarian development and age of the female, and are usually regulated by circadian rhythms under endocrine control, which are generally influenced by exogenous factors such as photoperiod and temperature (Turgeon \& McNeil 1983). Many studies have shown an effect of photoperiod, ovarian development, age and temperature on calling behavior in insects (Nordlund $\&$ Brady 1974; Swier et al. 1977; Howlader \& Gerber 1986; Gerber \& Howlader 1987; Cusson et al. 1994a,b; Delisle \& Simard 2003; Da Silva et al. 2006).

Our results demonstrate that $P$. sequax spends about $11 \mathrm{~d}$ as pupae, and females might be capable of compensating a longer pupal period by calling earlier than females with a shorted pupal period. Similar studies with P. unipuncta, a species in North America and Azores which consists of migratory and non-migratory populations, showed that migratory and non-migratory individuals have adopted different behavioral and physiological responses to temperature and photoperiod (McNeil \& Tobe 2001). Calling behavior and rates of biosynthesis of juvenile hormone were initiated significantly earlier in adults of the non-migratory Azorean population (McNeil et al. 2000). Recent studies report the presence of 


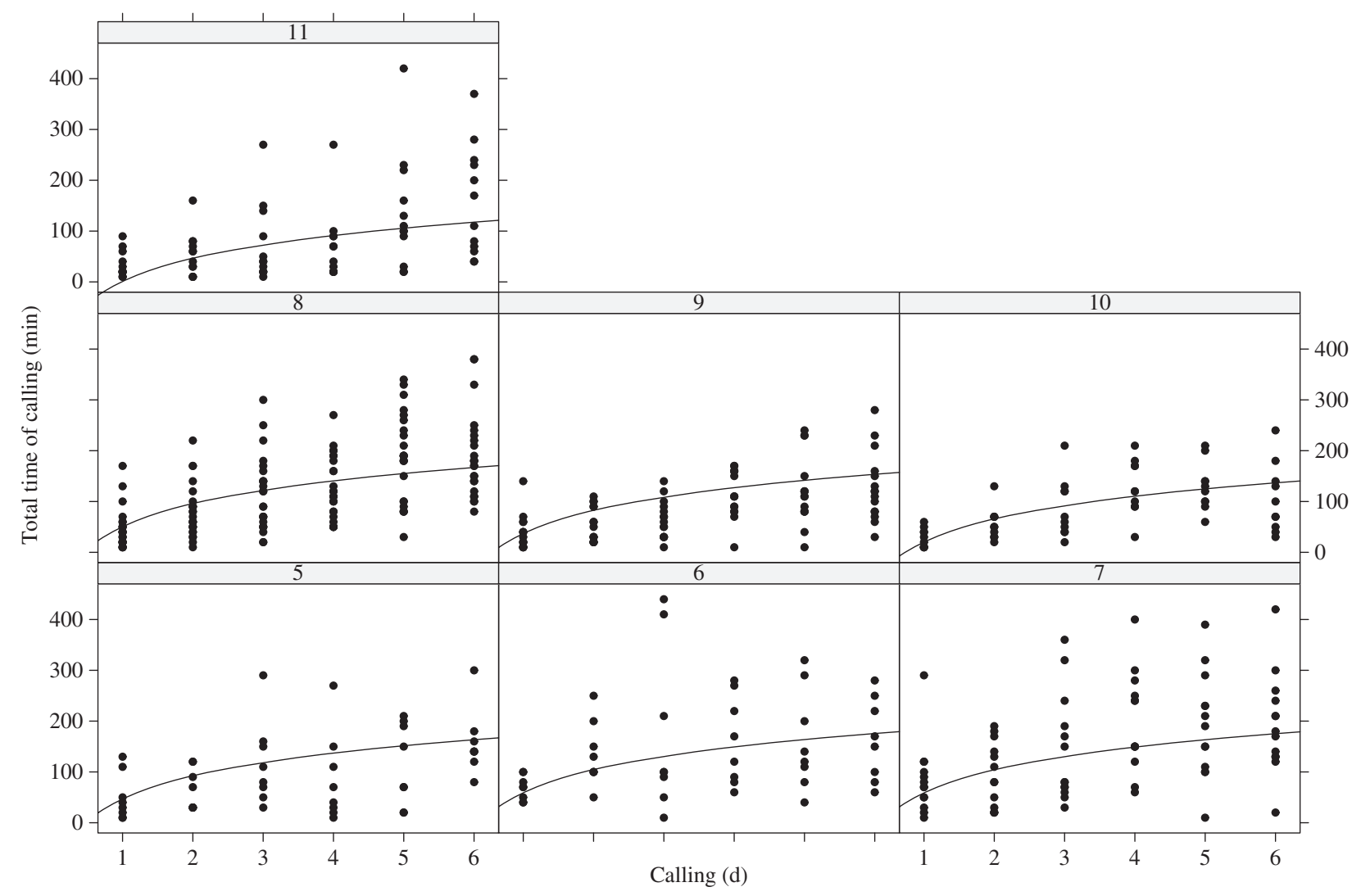

Fig. 3: Relationship between calling day, F-value $=151.64, \mathrm{p}$-value $=0.0001$, calling length and pupal period $(5,6, \ldots, 11$ respectively) F-value $=$ $13.69, \mathrm{p}$-value $=0.0004$ of virgin females of $P$. sequax in the scotophase at a temperature of $25 \pm 5^{\circ} \mathrm{C}$ and a photoperiod of $12 \mathrm{D}: 12 \mathrm{~L}$ and of $70 \%$ $\mathrm{RH},(\mathrm{n}=90)$.

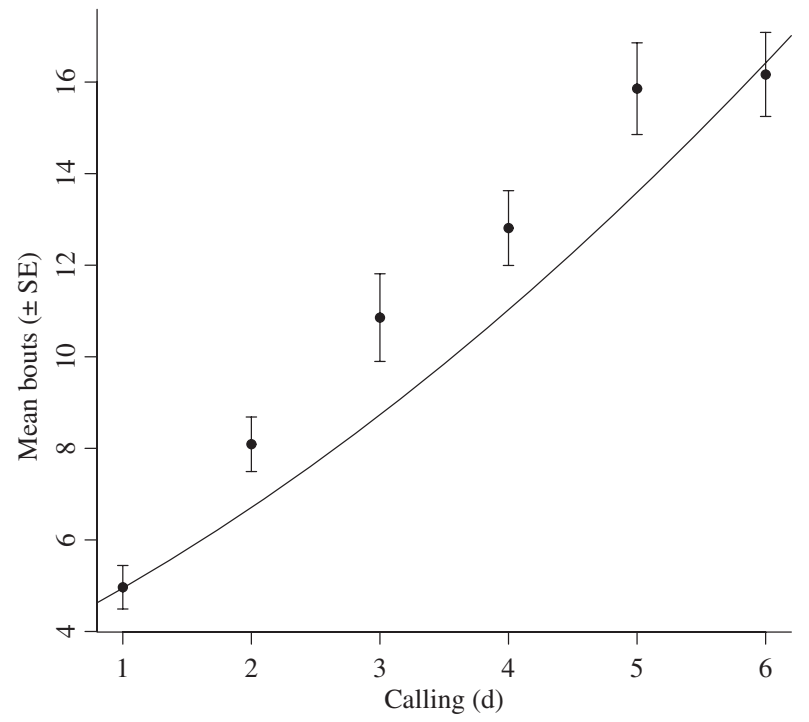

Fig. 4: Relationship between days since first calling and mean number of calling bouts of virgin females of $P$. sequax in the scotophase at a temperature of $25 \pm 5^{\circ} \mathrm{C}$ and a photoperiod of $12 \mathrm{D}: 12 \mathrm{~L}$ and $70 \%$ $\mathrm{RH}(\mathrm{n}=90)$, F-value $=202.251$, p-value 0.0001 . populations of $P$. sequax in other Brazilian regions, indicating the migratory behavior of this insect (A. Reis, E. R. Lima \& Â. A. Almeida, unpublished data). Possibly, females of P. sequax that emerge earlier and call later may show a larger propensity to migrate to other regions in search of favorable conditions. Females that emerge later and call earlier may show propensity to non-migrant behavior. To this end, the calling behavior and pupal period of resident and migratory populations of $P$. sequax should be compared. From an ecological perspective, it seems unlikely that the physiological processes involved in pheromone production will be identical in migratory and resident populations of $P$. sequax. In conclusion, this study shows that the calling behavior and pheromone release of $P$. sequax are affected by length of pupal period and days since first calling.

\section{Acknowledgements}

The authors thank Dr Arne Janssen and Prof. Flávia M.S. Carmo for valuable comments and corrections 
of the manuscript. Helpful comments on an earlier draft of this manuscript were made by two anonymous reviewers. Funding was provided by CAPES Foundation scholarship to A.A. Almeida, and CNPQ for the scholarship to E.R. Lima.

\section{Literature Cited}

Cardé, R. T. \& Baker, T. C. 1984: Sexual communication with pheromones. In: Chemical Ecology of Insects (Bell, W. J. \& Cardé, R. T., eds). Chapman and Hall, New York, USA pp. 356-383.

Crawley, M. J. 2002: Statistical Computing: An Introduction to Data Analysis Using S-plus. Wiley, Oxford. 761 pp.

Cusson, M. \& McNeil, J. N. 1989: Involvement of juvenile hormone in the regulation of pheromone release activities in a moth. Science 243, 210-212.

Cusson, M., Yagi, K. J., Tobe, S. S. \& McNeil, J. N. 1993: Identification of release products of corpora allata of male and female armyworm moths, Pseudaletia unipuncta. J. Insect Physiol. 39, 775-783.

Cusson, M., Tobe, S. S. \& McNeil, J. N. 1994a: Juvenile hormones: their role in the regulation of the pheromone communication system of the armyworm moth, Pseudaletia unipuncta. Arch. Insect Biochem. Physiol.

25, 329-345.

Cusson, M., Yu, G. C., Carruthers, K., Wyatt, R. G., Tobe, S. S. \& McNeil, J. N. 1994b: Regulation of vitellogenin production in armyworm moths, Pseudaletia unipuncta. J. Insect Physiol. 40, 129-136.

Da Silva, E. L., de Carvalho, C. M., do Nascimento, R. R., Mendonça, A. L., da Silva, C. E., Gonçalves, G. B., de Freitas, M. D. T. \& Sant'Ana, A. E. G. 2006: Reproductive behaviour of the Annona fruit borer, Cerconota anonella. Ethology 112, 971-976.

Delisle, J. \& Simard, J. 2003: Age-related changes in the competency of the pheromone gland and the pheromonotropic activity of the brain of both virgin and mated females of two Choristoneura species. J. Insect Physiol. 49, 91-97.

Gerber, H. G. \& Howlader, A. M. 1987: The effects of photoperiod and temperature on calling behaviour and egg development of the bertha armyworm, Mamestra configurata (Lepidoptera: Noctuidae). J. Insect Physiol. 33, 429-436.

Han, E. N. \& Gatehouse, A. G. 1991a: Genetics of precalling period in the oriental armyworm, Mythimna separata (Walker) (Lepidoptera: Noctuidae), and implications for migration. Evolution 45, 1502-1510.

Han, E. N. \& Gatehouse, A. G. 1991b: Effect of temperature and photoperiod on the calling behavior of a migratory insect, the oriental Armyworm Mythimna separata. Physiol. Entomol. 16, 419-427.
Hou, L. M. \& Sheng, F. C. 2000: Calling behaviour of adult female Helicoverpa armigera (Hubner) (Lepidoptera: Noctuidae) of overwintering generation and effects of mating. J. Appl. Entomol. 124, 71-75.

Howlader, A. M. \& Gerber, H. G. 1986: Calling behavior of bertha armyworm, Mamestra configurata (Lepidoptera: Noctuidae). Can. Entomol. 118, 735-743.

Kingan, T. G., Thomas-Laemont, P. A. \& Raina, A. K. 1993: Male accessory gland factors elicit change from virgin to mated behavior in the female corn earworm moth Helicoverpa zea. J. Exp. Biol. 183, 61-76.

McNeil, J. N. \& Tobe, S. S. 2001: Flights of fancy: possible roles of allatostatin and allatotropin in migration and reproductive success of Pseudaletia unipuncta. Peptides 22, 271-277.

McNeil, J. N., Miller, D., Laforge, M. \& Cusson, M. 2000: The biosynthesis of juvenile hormone its degradation and titres in females of the true armyworm: a comparison of migratory and non-migratory populations. Physiol. Entomol. 25, 103-111.

Nordlund, D. A. \& Brady, U. E. 1974: Calling behavior of female Plodia interpunctella (Hubner) (Lepidoptera: Pyralidae) under 2 light regimes. Environ. Entomol. 3, 793-796.

Picimbon, J., Becard, J. M., Sreng, L., Clement, J. L. \& Gardenne, C. 1995: Juvenile hormone stimulates pheromonotropic brain factor release in the female black cutworm, Agrotis ipsilon. J. Insect Physiol. 41, 377-382.

R Development Core Team. 2006. R: A Language and Environment for Statistical Computing. R Foundation for Statistical Computing, Vienna, Austria. Available at: http://www.R-project.org, accessed 10/8/2007.

Rafaeli, A. \& Bober, R. 2005: The effect of the juvenile hormone analog, fenoxycarb on the PBAN-receptor and pheromone production in adults of the moth Helicoverpa armigera: an aging hormone in adult females? J. Insect Physiol. 51, 401-410.

Raina, A. K. \& Klun, J. A. 1984: Brain factor control of sex pheromone production in the female corn earworm moth. Science 225, 531-533.

Salvadori, R. J. \& Parra, P. R. J. 1990: Seleção de dietas artificiais para Pseudaletia sequax (Lepidoptera: Noctuidae). Pesqui. Agropecu. Bras. 25, 1701-1713.

Swier, S. R., Rings, W. R. \& Musick, J. G. 1977: Agerelated calling behavior of black cutworm, Agrotis ipsilon. Ann. Entomol. Soc. Am. 70, 919-924.

Turgeon, J. J. \& McNeil, J. N. 1982: Calling behaviour of the armyworm, Pseudaletia unipuncta. Entomol. Exp. Appl. 31, 402-408.

Turgeon, J. J. \& McNeil, J. N. 1983: Modifications in the calling behavior of Pseudaletia unipuncta (Lepidoptera: Noctuidae) induced by temperature conditions during pupal and adult development. Can. Entomol. 115, 1015-1022. 